\title{
MULTI-CYCLE WASHING OF COTTON AND THE RESULTS IN MANNER OF DP
}

\author{
Fatma Gündüz BALPETEK ${ }^{1}$, Ebru BOZACI ${ }^{2}$, Pelin Seçim KARAKAYA ${ }^{1}$, Esen ÖZDOĞAN $^{2}$ \\ Aslı DEMIR ${ }^{2}$, Tülay GÜLÜMSER ${ }^{2}$ \\ ${ }^{I}$ Textile and Apparel Research-Application Center, Ege University, 35100 Bornova-Izmir, Turkey \\ ${ }^{2}$ Department of Textile Engineering, Faculty of Engineering, Ege University, 35100 Bornova- Izmir, Turkey
}

Received: 03.07.2018

Accepted: 13.11 .2018

\begin{abstract}
Washing processes, detergant agents, washing cycles and temperatures can often cause damage on fabrics. The aim of this work was to determine chemical and physical changes on cotton fabrics with different washing conditions. A Box-Bhenken statistical design was used to evaluate the effect of washing temperature $\left(40-50-60^{\circ} \mathrm{C}\right)$, number of washing $(10,30,50)$ and washing agent (only water, base detergent, detergent with bleaching agent) on the average degree of polymerization. The effect of multiple washes on cotton fabrics was evaluated by means of average polymerization degree, tensile strength, whiteness index and scanning electron microscopy. Whiteness index decreased significantly using with base detergent and bleaching agent containing detergent, whereas washing with only water did not affect significantly to whiteness index, with increasing number of washing. However, temperature $(p>0.05)$ individually were not found statistically significant for whiteness index. As number of washing and temperature increased, tensile strength values decreased. Also, washing agent $(\mathrm{p}>0.05)$ individually were not found statistically significant for tensile strength. When evaluated in terms of average polymerization degree values, after the washings with base detergent and bleaching agent containing detergent, there is a greater decrease in the average polymerization degree relative to the only water washings. While the temperature increased in washing process, the average polymerization degree decreased and the lowest average polymerization degree was obtained at $60{ }^{\circ} \mathrm{C}$ and 50 washing cycles SEM images indicate that number of washing and the content of detergent are important parameters in the washing process. The worst image in this study was obtained with 50 washes using detergent containing bleaching agent. Washing processes cause undesirable results on the surface of fabrics.
\end{abstract}

Keywords: Cotton, Box-Behnken, Average Polymerisation Degree, Laundry, Detergent

Corresponding Author: Aslı DEMIR asli.demir@ege.edu.tr / DOI: 10.32710/ tekstilvekonfeksiyon.493100

\section{INTRODUCTION}

The garments are used in daily life and they are mostly exposed to the effects of laundering process. During this processes, the fabrics can be subjected to several changes depending on washing conditions [1]. The damages of laundering process especially show itself as consequential losses after repeated washings; significantly affects the life time of the fabric [2]. Abrasion and the deterioration of their appearance characteristics caused by laundry process are the key factors in determining service life of fabrics [3].

The results of laundry process depend on a great number of factors related to detergents, washing temperature, water hardness, type of washing machine, washing program, spinning cycle, structure and type of fabric, laundry load, etc. As the number of washing increases, both chemical and physical changes can occur including the dimensional and structural changes, decrease in degree of polymerization, breakdown of molecular structure, loss of tensile strength, abrasion and color change become remarkable [2].
In the broadest sense, laundering can be defined as both the removal by water or aqueous surfactant solution of poorly soluble matter and the dissolution of water-soluble impurities from textile surfaces [4]. Laundering process include textile materials, soil, water, detergents and washing machine [5]. The effect of specific factors can be corresponded by a washing cycle, within which is the circle dealing with water, which connects the factors in the process [6]. Stamminger et al. (2005) published an average water consumption of $59 \mathrm{~L}$ per wash cycle with a load size of $5 \mathrm{~kg}$ for washing machines built in 2000 [7]. According to Pakula and Stamminger (2010), an average consumption per wash cycle is estimated $60 \mathrm{~L}$ for all European countries [8].

The selection of washing temperature, frequency and type of detergent are very much culturally dependent. In Europe, the average washing temperature is $45.8^{\circ} \mathrm{C}$. A worldwide comparative study of energy and water consumption of automated laundry washing showed that the energy use per wash cycle mainly depends on the average washing 
temperature $[8,9]$. In contrast with these consumer washing habits, according to the consumer surveys in Turkey the average washing temperature is $60{ }^{\circ} \mathrm{C}$ for the white fabrics and $40{ }^{\circ} \mathrm{C}$ for the coloured fabris [10]. Water and energy consumption of domestic laundering for average load of 3,7 $\mathrm{kg} /$ cycle (for Turkey) is given in Table1.

Table 1. Yearly energy and water consumption for automatic laundry washing per household in Turkey [8]

\begin{tabular}{|l|c|}
\hline Number of household year $(\times 1,000)$ & 17,698 \\
\hline Average wash temperature $\left({ }^{\circ} \mathrm{C}\right)$ & 42,5 \\
\hline Energy consumption/wash cycle $(\mathrm{kWh})$ & 0,63 \\
\hline Number of wash cycles/year & 135 \\
\hline Energy consumption/household/year $(\mathrm{kWh})$ & 85,6 \\
\hline Water consumption/household/year $\left(\mathrm{m}^{3}\right)^{\mathrm{a}}$ & 6,8 \\
\hline
\end{tabular}

${ }^{\mathrm{a} B a s e d}$ on $50 \mathrm{~L}$ water consumption per wash cycle

The basic necessity for a laundering process is to remove various soils and keep the main characteristic of textile materials. The main components of detergent formulation are surfactants, ion exchangers, soil anti-redeposition agents, enzymes, fluorescent whitening agents, foam regulators, bleach activators, soil repellents, polycarboxylate cobuilders. etc Surfactants loosen the soil, deflocculates them and stabilize their aqueous dispersion. This effect is enhanced by presence of anionic and non-ionic surfactants in the washing bath. The soil removal process is also improved by quality of water, proper wash time, mechanical action, and temperature. The gathering of deposits can cause negative effects, e.g. harsh and stiff hand, progress in degradation and tearing, as well as reduced usability of the textiles. The cumulative effects of them influence on the changes of textiles during laundering $[4,6]$. The frequent washing cycles can also cause the fibre surface modification as a result of fibre swelling capacity in the alkaline detergent bath superimposed by mechanical agitation. Therefore, the selection of washing temperature, frequency and type of detergent are very important for textile quality $[6,9]$.

Different quality associations are specialized for appropriate laundering methods including the Research Institute Hohenstein (Germany) and RAL-GZ 992. The Swiss Institute EMPA - Research Institute of Material Science and Technology has also determined a scale of evaluation of secondary laundering effect. The secondary laundering effects is composed of several changes containing degree of polymerization, breakdown of molecular structure, loss of tensile strength, discoloration and overall change in appearance [11].

In this study, the impact of multiple washing cycles on cotton fabrics were monitored through average polymerisation degree, tensile strength, whiteness index and scanning electron microscopy.

\section{MATERIALS AND METHODS}

\subsection{Materials and Reagents}

In the study scoured, $100 \%$ cotton woven plain fabric was used. The mass per unit area was $145,7 \mathrm{~g} / \mathrm{m} 2$. Yarn linear density was $\mathrm{Ne} 21$ in weft direction and $\mathrm{Ne} 20$ in warp direction. Fabric tightness was 21 thread $/ \mathrm{cm}$ in weft direction and 29 thread/cm in warp direction. Chemicals used in experiments are given in Table 2.

Table 2. Chemicals used in the experiments

\begin{tabular}{|l|l|}
\hline Chemicals & Brand \\
\hline Base Detergent (without bleaching agent) & Unilever \\
\hline Bleaching agent containing detergent & Unilever \\
\hline Copper (II) Ethylenediamine & Merck \\
\hline Sulfuric acid (\%97-99) & Merck \\
\hline
\end{tabular}

\subsection{Methods}

The washing procedures were applied by using Arcelik 7103 HE washing machine, cotton program was used. Washing parameters used in experiments are given in Table 3. The whitening index of fabrics (WI CIE) was measured according to ASTM E313 standard [12] by HunterLab UltraScan Pro Spectrophotometer under a D65 light source. Measurements were made for an area of 30 $\mathrm{mm}$ in diameter and a $10^{\circ}$ observer. For each sample, whiteness measurements were done by 10 repetitions. Tensile strength tests were carried out according to ISO 13934-1 [13] by using Zwick Z010 instrument. Five samples for each sample were tested, and averages of the test results were calculated. Morphological changes on the surface of the fabrics were observed using a Quanta 250FEG SEM (1000x) at a typical accelerating voltage of $15 \mathrm{kV}$. Fabric samples were gold coated using a Emitech K550X sputter coater before the SEM images. The average degree of polymerization of cotton fabrics were measured according to AATCC 82 (Fluidity of Dispersions of Cellulose from Bleached Cotton Cloth) standard [14] by Schott CK300 device.

Table 3: Washing parameters

\begin{tabular}{|l|l|}
\hline Washing Parameters & Test Condition \\
\hline Temperature & $40^{\circ} \mathrm{C}, 50^{\circ} \mathrm{C}, 60^{\circ} \mathrm{C}$ \\
\hline Water Hardness & $30^{\circ} \mathrm{FH}$ \\
\hline Washing Load & $3 \mathrm{~kg}$ \\
\hline Detergent Dosage & $150 \mathrm{~g}$ \\
\hline \multirow{3}{*}{ Washing Agent } & Base detergent \\
\cline { 2 - 2 } & Bleaching agent containing detergent \\
\cline { 2 - 2 } & Water (without detergent) \\
\hline Number of repetition & $10,30,50$ \\
\hline $\begin{array}{l}\text { Amount of water used } \\
\text { per washing cycle }\end{array}$ & $85 \mathrm{~L}$ \\
\hline
\end{tabular}

The base detergent used in this study, consists of detergent ingredients such as surfactants, builders, foam regulators, corrosion inhibitors, fillers. Detergent containing $15 \%$ bleaching system is composed of base detergent and $15 \%$ bleaching system $[15,16]$

The Box-Behnken response surface experimental design basically involves three major steps, performing the statistically designed experiments, estimating the coefficients in a mathematical model, and predicting the response and checking the adequacy of the model [17]. Analyses of the three dimensional response surface plots helped to favourably investigate the interactions between any two variables, and locate the optimum range of the variables efficiently so that the average polymerization degree response was maximized. Totally 15 runs were 
required to cover all points according to the 3-level factorial design with 3 replicates on center point [18].

In this study, Box-Behnken test design was used estimating the average degree of polymerization by using washing parameters such as washing agent type, number of washing and temperature. The low, middle, and high levels of each variable were designated as $-1,0$, and +1 , and were given in Table 4. Box Behnken design used in estimating the average degree of polymerization and the codes of the samples are given in Table 5.

\section{RESULTS AND DISCUSSION}

Several variables have been tested simultaneously with using RSM with a minimum number of trials, in accordance with experimental designs elucidating interactions between variables [19]. Models with high regression from $95 \%$ can be accepted. In other words, the difference between experimental and estimated data is less than $\% 5$. Another parameter is the p-value applied to the selected model and coefficients to examine the significance of each parameter in the equation. A p-value less than 0.05 indicates that model terms are significant. If the $p$-value is greater than 0.05 , the possibility of existence of another coefficient in equation is greater than $95 \%$ that means the provided parameter cannot be significant $[20,22]$. The three centerpoint runs were added to provide a measure stability and inherent variability.

A second-order polynomial equations was used to express the average polymerization degree, whiteness and tensile strength of washed cotton fabrics as a function of independent variables (Table 4), where A, B, C represents the code of such as temperature $\left({ }^{\circ} \mathrm{C}\right)$, washing agent and mumber of washing, respectively. ANOVA and estimated regression coefficients, regression analyses, measured and fitted values of samples were evaluated with Minitab Release 12.1 program and the results are given in Table 68.

Table 4. Box Behnken design used in experiments

\begin{tabular}{|ll|c|c|c|}
\multicolumn{1}{l|}{} & -1 & 0 & $\mathbf{+ 1}$ \\
\hline (A) & Temperature $\left({ }^{\circ} \mathrm{C}\right)$ & $\mathbf{4 0}$ & $\mathbf{5 0}$ & $\mathbf{6 0}$ \\
\hline (B) & Washing Agent & Water & Base Detergent & Bleaching agent containing detergent \\
\hline (C) & Number of Washing & 10 & $\mathbf{3 0}$ & $\mathbf{5 0}$ \\
\hline
\end{tabular}

Table 5. Sample codes used in experiments

\begin{tabular}{|c|c|c|l|c|}
\hline Samples & Box Behnken Code & Temperature $\left({ }^{\circ} \mathbf{C}\right)$ & \multicolumn{1}{|c|}{ Washing Agent } & Number of Washing \\
\hline 1 & 000 & 50 & Base detergent & 30 \\
\hline 2 & $-0+$ & 40 & Base detergent & 50 \\
\hline 3 & 000 & 50 & Base detergent & 30 \\
\hline 4 & $+0+$ & 60 & Base detergent & 30 \\
\hline 5 & ++0 & 60 & Bleaching agent containing detergent & 50 \\
\hline 6 & $0++$ & 50 & Bleaching agent containing detergent & 30 \\
\hline 7 & -+0 & 40 & Bleaching agent containing detergent & 10 \\
\hline 8 & $-0-$ & 40 & Base detergent & 30 \\
\hline 9 & --0 & 40 & Water & 30 \\
\hline 10 & +-0 & 60 & Water & 10 \\
\hline 11 & $0+-$ & 50 & Bleaching agent containing detergent & 10 \\
\hline 12 & $0--$ & 50 & Water & 50 \\
\hline 13 & $0-+$ & 50 & Water & 30 \\
\hline 14 & 000 & 50 & Base detergent & 10 \\
\hline 15 & $+0-$ & 60 & Base detergent & \\
\hline
\end{tabular}

Table 6. ANOVA and estimated regression coefficients

\begin{tabular}{|c|c|c|c|c|c|c|c|c|c|c|c|c|}
\hline \multirow[b]{2}{*}{ Term } & \multicolumn{4}{|c|}{ WI CIE } & \multicolumn{4}{|c|}{ DP } & \multicolumn{4}{|c|}{$\begin{array}{l}\text { Maximum breaking force }(\mathrm{N}) \text { on warp } \\
\text { direction }\end{array}$} \\
\hline & Coef. & $\begin{array}{l}\text { St. } \\
\text { Dev }\end{array}$ & $T$ & $P$ & Coef. & St. Dev & $\mathrm{T}$ & $P$ & Coef. & St. Dev & $T$ & $P$ \\
\hline Constant & 130,58 & 2,100 & 62,177 & 0,000 & 3621,0 & 12,501 & 289,66 & 0,000 & 479,6 & 7,719 & 62,134 & 0 \\
\hline A & 1,19 & 1,286 & 0,927 & 0,396 & $-17,7$ & 7,655 & $-2,319$ & 0,068 & $-22,88$ & 4,727 & $-4,841$ & 0,005 \\
\hline $\mathrm{B}$ & 32,59 & 1,286 & 25,338 & 0,000 & $-54,3$ & 7,655 & $-7,087$ & 0,001 & $-6,37$ & 4,727 & $-1,347$ & 0,236 \\
\hline $\mathrm{C}$ & $-8,02$ & 1,286 & $-6,237$ & 0,002 & $-109,2$ & 7,655 & $-14,272$ & 0,000 & $-39,43$ & 4,727 & $-8,342$ & 0 \\
\hline$A^{*} A$ & 4,21 & 1,893 & 2,225 & 0,077 & 66,6 & 11,268 & 5,913 & 0,002 & $-2,7$ & 6,958 & $-0,389$ & 0,714 \\
\hline $\mathrm{B}^{*} \mathrm{~B}$ & $-23,23$ & 1,893 & $-12,270$ & 0,000 & 87,6 & 11,268 & 7,776 & 0,001 & $-2,91$ & 6,958 & $-0,418$ & 0,693 \\
\hline $\mathrm{C}^{*} \mathrm{C}$ & $-0,82$ & 1,893 & $-0,435$ & 0,682 & 55,6 & 11,268 & 4,937 & 0,004 & $-19,36$ & 6,958 & $-2,783$ & 0,039 \\
\hline$A^{*} B$ & $-2,70$ & 1,819 & $-1,484$ & 0,198 & 8,7 & 10,826 & 0,808 & 0,456 & $-9,61$ & 6,685 & $-1,438$ & 0,21 \\
\hline$A^{*} C$ & $-0,77$ & 1,819 & $-0,423$ & 0,690 & 2,7 & 10,826 & 0,254 & 0,810 & $-7,4$ & 6,685 & $-1,107$ & 0,319 \\
\hline $\mathrm{B}^{*} \mathrm{C}$ & $-5,80$ & 1,819 & $-3,191$ & 0,024 & 49,3 & 10,826 & 4,549 & 0,006 & $-3,91$ & 6,685 & $-0,585$ & 0,584 \\
\hline
\end{tabular}


Table 7. Regression analyses (quadratic response surface model fitting) for whitening index (WICIE), average polymerization degree (DP), maximum breaking force $(\mathrm{N})$ on warp direction

\begin{tabular}{|c|c|c|c|c|c|c|c|c|c|c|c|c|c|c|c|c|c|c|}
\hline \multirow[b]{2}{*}{ Source } & \multicolumn{6}{|c|}{ WI CIE } & \multicolumn{6}{|c|}{$\mathrm{DP}$} & \multicolumn{6}{|c|}{$\begin{array}{l}\text { Maximum breaking force }(\mathrm{N}) \text { on warp } \\
\text { direction }\end{array}$} \\
\hline & $\mathrm{dF}$ & Seq SS & Adj SS & Adj MS & $\mathrm{F}$ & $\mathrm{P}$ & $\mathrm{dF}$ & Seq SS & Adj SS & Adj MS & $\mathrm{F}$ & $\mathrm{P}$ & $\mathrm{dF}$ & Seq SS & Adj SS & Adj MS & $\mathrm{F}$ & $P$ \\
\hline Regression & 9 & 11314,5 & 11314,53 & 1257,17 & 95,01 & 0,000 & 9 & 180687 & 180687 & 20076,3 & 42,82 & 0,000 & 9 & 18997,7 & 18997,7 & 2110,86 & 11,81 & 0,007 \\
\hline Linear & 3 & 9021,4 & 9021,41 & 3007,14 & 227,25 & 0,000 & 3 & 121549 & 121549 & 40516,5 & 86,43 & 0,000 & 3 & 16951,6 & 16951,6 & 5650,54 & 31,61 & 0,001 \\
\hline Square & 3 & 2126,9 & 2126,86 & 708,95 & 53,58 & 0,000 & 3 & 49099 & 49099 & 16366,2 & 34,91 & 0,001 & 3 & 1396,1 & 1396,1 & 465,36 & 2,60 & 0,164 \\
\hline \multirow[t]{2}{*}{ Interaction } & 3 & 166,3 & 166,26 & 55,42 & 4,19 & 0,079 & 3 & 10039 & 10039 & 3346,3 & 7,14 & 0,030 & 3 & 650,0 & 650,0 & 216,68 & 1,21 & 0,396 \\
\hline & \multicolumn{6}{|c|}{ R-Sq $=99,4 \%$} & \multicolumn{6}{|c|}{$\mathrm{R}-\mathrm{Sq}=98,7 \%$} & \multicolumn{6}{|c|}{ R-Sq $=95,5 \% \quad$ R-Sq(adj) $=87,4 \%$} \\
\hline
\end{tabular}

Table 8. Measured and fitted values of samples

\begin{tabular}{|c|c|c|c|c|c|c|c|}
\hline \multirow[b]{2}{*}{ Sample Code $\left(^{*}\right)$} & \multirow[b]{2}{*}{ Samples } & \multicolumn{2}{|c|}{ WI CIE } & \multicolumn{2}{|c|}{$\begin{array}{c}\text { Average Polymerisation } \\
\text { Degree }\end{array}$} & \multicolumn{2}{|c|}{$\begin{array}{c}\text { Maximum breaking force }(\mathrm{N}) \\
\text { on warp direction }\end{array}$} \\
\hline & & Measured & Fit & Measured & Fit & Measured & Fit \\
\hline 50C,BD,30NW & 1 & 130,584 & 130,584 & 3621 & 3621 & 479,6 & 479,6 \\
\hline $40 \mathrm{C}, \mathrm{BD}, 50 \mathrm{NW}$ & 2 & 122,710 & 125,527 & 3627 & 3649 & 436,613 & 448,388 \\
\hline $50 \mathrm{C}, \mathrm{BD}, 30 \mathrm{NW}$ & 3 & 130,584 & 130,584 & 3621 & 3621 & 479,6 & 479,6 \\
\hline 60C,BD,50 NW & 4 & 124,847 & 126,373 & 3609 & 3619 & 381,34 & 387,822 \\
\hline 60C,BA,30 NW & 5 & 143,774 & 142,647 & 3707 & 3712 & 437,1 & 435,123 \\
\hline 50C,BA,50 NW & 6 & 125,693 & 125,293 & 3665 & 3650 & 412,127 & 407,621 \\
\hline $40 \mathrm{C}, \mathrm{BA}, 30 \mathrm{NW}$ & 7 & 148,077 & 145,660 & 3737 & 3730 & 507,39 & 500,12 \\
\hline 40C,BD,10 NW & 8 & 141,559 & 140,033 & 3883 & 3873 & 518,933 & 512,451 \\
\hline $40 \mathrm{C}, \mathrm{W}, 30 \mathrm{NW}$ & 9 & 73,963 & 75,089 & 3861 & 3856 & 491,647 & 493,624 \\
\hline $60 \mathrm{C}, \mathrm{W}, 30 \mathrm{NW}$ & 10 & 80,454 & 82,871 & 3796 & 3803 & 459,817 & 467,086 \\
\hline $50 \mathrm{C}, \mathrm{BA}, 10 \mathrm{NW}$ & 11 & 149,002 & 152,946 & 3753 & 3770 & 480,557 & 494,309 \\
\hline $50 \mathrm{C}, \mathrm{W}, 10 \mathrm{NW}$ & 12 & 75,764 & 76,163 & 3962 & 3977 & 494,71 & 499,215 \\
\hline 50C,W,50 NW & 13 & 75,671 & 71,728 & 3677 & 3660 & 441,933 & 428,181 \\
\hline $50 \mathrm{C}, \mathrm{BD}, 30 \mathrm{NW}$ & 14 & 130,584 & 130,584 & 3621 & 3621 & 479,6 & 479,6 \\
\hline $60 \mathrm{C}, \mathrm{BD}, 10 \mathrm{NW}$ & 15 & 146,771 & 143,955 & 3854 & 3832 & 493,257 & 481,482 \\
\hline
\end{tabular}

$\left({ }^{*}\right)$ Temperature: ${ }^{\circ} \mathrm{C}$, Bleaching agent containing detergent: BA, Base detergent: BD, Water:W, Number of Washing:NW

\subsection{Whiteness Evaluation}

Under D65 light source corresponding to daylight, the whitening index (WI CIE) of multiwashed samples were measured by HunterLab UltraScan Pro Spectrophotometer. Whitening index of unwashed cotton fabric was 72,21. Whitening index of washed cotton fabrics (WI CIE) were evaluated with Minitab Release 12.1 program and the results are given in Table 6-8.

Also, regression analysis for whiteness degree was calculated. The regression equation is $\mathrm{WI} \mathrm{CIE}=397-3,68$ $A-229$ B - 0,11 C + 0,0421 A*A - 0,169 A*B - 0,0038 A* + $0,013 B^{*} C+60,5 B^{*} B-0,00206 C^{*} C$

$$
(S=6,543 \quad R-S q=98,1 \% \quad R-S q(\operatorname{adj})=94,7 \%)
$$

The regression formula provided good explanation of the relationship among the independent variables and the response. Washing agent and number of washing $(p<0.05)$ were found significant, whereas temperature $(p>0.05)$ individually were not statistically significant for whiteness index (Table 7). Their interaction between temperature washing agent and temperature - number of washing $(p>$ 0.05 ) were not found significant. However washing agent and number of washing $(p<0.05)$ has significant difference as statistically on the whiteness index (Table 7). Therefore, the three dimensional response surface plot related with the effect of washing agent and number of washing on whitening index was given in Figure 1.

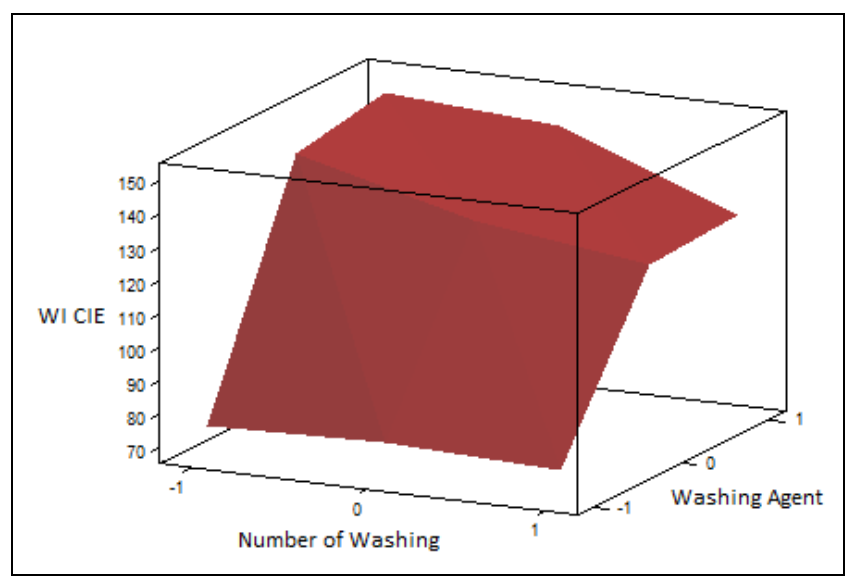

Figure 1. The three dimensional response surface plot related with the effect of washing agent and number of washing on whitening index (Number of Washing (10 washing cycle:1, 30: washing cycle:0, 50: washing cycle:+1), Washing Agent (Water:-1, Base Detergent: 0, Bleaching agent containing detergent:+1)) 
Compared to the unwashed cotton fabric, the whitening index increases after washing cycles for all samples. In general, it can be said that the whitening index of the samples washed with bleaching agent containing detergent were increased more than other washing agents. The removal of impurities on the fabric and the components in the washing agent may promote this situation.

When number of washing is considered there is obviously difference between only water and detergent containing solution. As the number of washing cycles increases, whiteness index is not significantly affected in washing with only water, while the whiteness index decreases significantly with increasing number of washing with base detergent and bleaching agent containing detergent. This may be to be due to the accumulation of washing agent and water hardness ions on fabrics.

\subsection{Average Polymerization Degree Evaluation}

The number of monomer molecules linked together in the polymer molecules is called the polymerization degree. The average degree of polymerization for cotton fabrics was measured by Schott CK300 devices. Average polymerization degree of washed cotton fabrics (DP) were evaluated with Minitab Release 12.1 program and the results are given in Table 6-8. Also, average polymerization degree of unwashed cotton fabric was found as 4027,449 .

According to the results, the combination of washing agent, washing number and combination of these two variables used in washing significantly affects the average degree of polymerization at $95 \%$ confidence interval at 0.05 significance level. According to the regression analysis given in Table 7, the variables make a significant difference in linear $(P=0,000)$, squared $(P=0.001)$ or interaction $(P=$ $0.030)$ variance.

The correlation between the experimentally obtained OP values and the fitted OP values was found to be $96.4 \%$ (Table 7). This correlation value indicates the availability of experimentally obtained data.

Regression equation was calculated to estimate the average degree of polymerization for samples that were eliminated according to the Box-Behnken design. The regression equation is

$O P=5356-68,2 A+481 B-17,6 C+\left(0,666 A^{*} A\right)-(0,34$ $\left.A^{*} B\right)+\left(0,0138 A^{*} C\right)+\left(1,77 B^{*} C\right)-\left(125 B^{*} B\right)+\left(0,139 C^{*} C\right)$

( $\mathrm{S}=32,90$

$$
\mathrm{R}-\mathrm{Sq}=97,0 \% \quad \mathrm{R}-\mathrm{Sq}(\operatorname{adj})=91,7 \%)
$$

The washing agent and the number of washings has significant difference as statistically on the average polymerization degree (Table 7). Therefore, the three dimensional response surface plot related with the effect of washing agent and number of washing on average polymerization degree was given in Figure 2.

When the washed samples are compared with the unwashed fabric, a decrease in the average polymerization degree is observed after washing cycles. The average polymerization degree values decrease even after washing with only water without any chemical effect. This is mainly due to the mechanical effects of the washing machine. It is thought that water facilitates sliding over each other of macromolecule chains. When evaluated in general, after the washings with base detergent or bleaching agent containing detergent, there is a greater decrease in the average polymerization degree relative to the only water washings. This decrease is more significant by washing with bleaching agent containing detergent; also this change is thought due to the chemical effect of the bleaching agents. It is believed that in detergent containing bleach system, the oxidation of the bleach system constituents (percarbonate, TAED, peracids, etc.) causes breaks at the macromolecular level and the average polymerization degree were decreased.

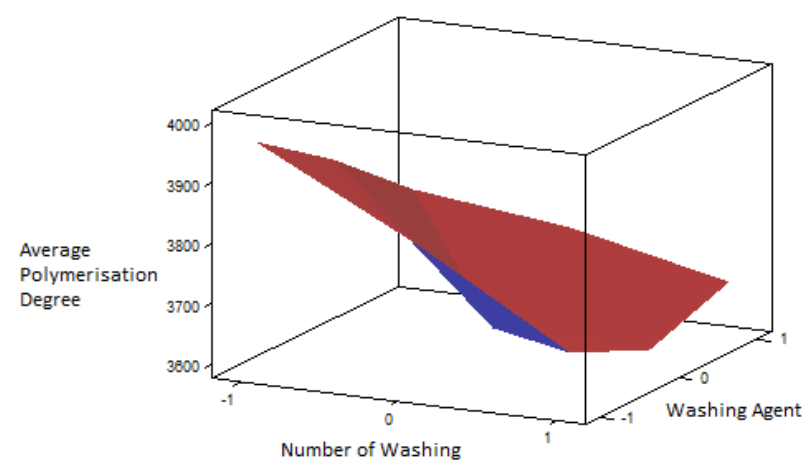

Figure 2. The three dimensional response surface plot related with the effect of washing agent and number of washing on average polymerization degree (Number of Washing (10 washing cycle:-1, 30: washing cycle:0, 50: washing cycle:+1), Washing Agent (Water:-1, Base Detergent: 0, Bleaching agent containing detergent:+1))

Both mechanical and chemical actions during washing attach reactive fibers groups, weakening fibers' structure, with a progressive damage in the molecular chain and a reduction in degree of polymerization (DP) [23]

When the temperature increased in washing process, the average polymerization degree decreased because of fiber deterioration. So, in this study the lowest average polymerization degree was obtained at $60^{\circ} \mathrm{C}$. In addition, with the number of washings, the mechanical damage of the fabric increased and the degree of polymerization decreased. Thus, the lowest polymerisation degree was obtained at the end of 50 washing cycles. Washing processes cause undesirable results on the surface of fabrics.

\subsection{Tensile Strength Evaluation}

The damage done by the bleach system to woven fabrics could possibly be quantified by measuring the tensile strength loss [21]. The tensile strength values of the fabrics measured by ISO 13934-1 method and maximum breaking force on warp direction of unwashed cotton fabric was 530,1 $\mathrm{N}$. Maximum breaking force $(\mathrm{N})$ on warp direction of washed cotton fabrics were evaluated with Minitab Release 12.1 program and the results are given in Table 6-8.

The correlation between the experimentally obtained tensile strength values and the fitted tensile strength values was found to be $95.5 \%$ (Table 7 ). This correlation value indicates the availability of experimentally obtained data. 
Regression equation was calculated and the equation is

TSwarp $=433+2,64 A+46,9 B+2,04 C-0,0270 A^{*} A-$ $0,638 A^{*} B-0,0370 A^{*} C+0,427 B^{*} C-8,10 B^{*} B-0,0484$ $\mathrm{C}^{*} \mathrm{C}$

$$
(S=11,83 R-S q=96,5 \% \quad R-S q(\operatorname{adj})=90,1 \%)
$$

The temperature and the number of washings has significant difference as statistically on the tensile strength (Table 7). Therefore, the three dimensional response surface plot related with the effect of temperature and number of washing on tensile strength was given in Figure 3.

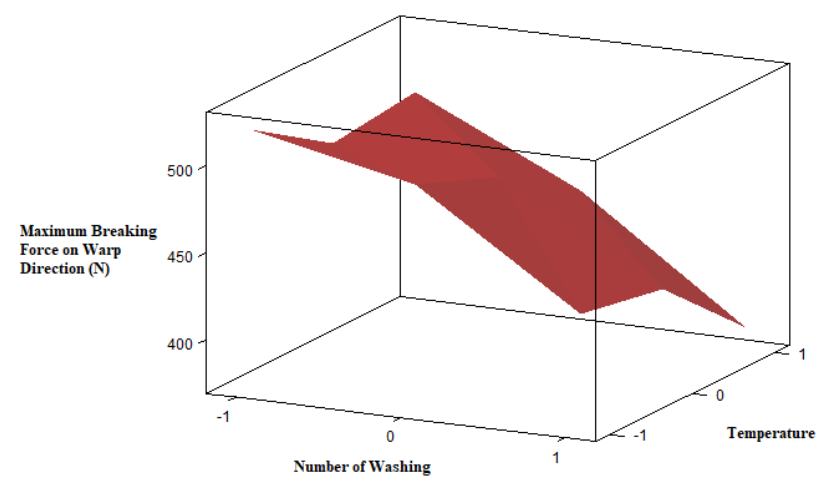

Figure 3. The three dimensional response surface plot related with the effect of temperature $\left({ }^{\circ} \mathrm{C}\right)$ and number of washing on tensile strength $(\mathrm{N})$ at warp direction (Number of Washing (10 washing cycle:-1, 30: washing cycle:0, 50: washing cycle:+1), Temperature: $40{ }^{\circ} \mathrm{C}:-1,50{ }^{\circ} \mathrm{C}: 0,60$ $\left.{ }^{\circ} \mathrm{C}:+1\right)$ )

The tensile strength values decrease as the number of washings increases for all samples. The value of the tensile strength is also reduced by the temperature increase. In the first 10 washing cycles, the reduction in tensile strength is less pronounced, but after 50 washing cycle this reduction is significant.

\subsection{SEM (Scanning Electron Microscope) Evaluations}

Morphological changes on fabric surfaces were observed using a Quanta 250FEG SEM. The SEM images of unwashed and washed cotton fabrics are shown in Figure 3.

Washing processes, detergent agents, washing cycles and temperatures can often accelerates damage of the fabrics. In this study, when the SEM images were examined in terms of the number of washings, it was observed that some deformation occurred on the surface depending on the mechanical effect with increasing number of washings. When sample images are examined, it is seen that the surface of the unwashed fabric is smoother than the washed fabrics. Repeated washings cause peeling in the surface layer of the fibers and formation of spiral cracks parallel to the fiber length.

Many detergents on the market contain bleach, and bleaches have some negative effects on laundry. It is understood from the images that the content of detergent is an important parameter in the washing process and that bleach-containing detergents cause more damage to the fabric than not containing one. As can be seen in the images the worst result in study was obtained with 50 washes with detergent containing bleach.

\section{CONCLUSION}

Textile products are subjected to multiple washing processes for cleaning and for this purpose usually detergents and bleachers which are developed for home laundry machines are used. In the composition of these detergents, perborate, bleaching agent and optical bleach are present. The mechanical effects of these detergents and washing machines cause various damages to the textile products and cause them to wear out over time.

Although there have been many studies and publications on the effect of washing on the mechanical properties of textiles, a limited number of studies have been conducted on the effect of the average degree of polymerization. In this study, it was attempted to explain that washing was effected not only physically but also chemically on fabrics. From this point of view chemical and physical changes on cotton fabrics was obtained with different washing conditions.

In the study, the effect of detergents (base detergent and detergent with bleaching agent), only water without detergent and the effect of washing conditions $\left(40,50\right.$ and $60^{\circ} \mathrm{C}$ and 10 , 30 and 50 washes) were examined and tensile strength, average polymerization degree, whiteness index measurement and SEM images were measured. The results of the average polymerization degree measurements were also evaluated statistically and the formula needed for estimation was determined. Suitable experimental arrangements help to obtain reliable results and classifications.

As a result of the whiteness index measurements of the fabrics, an increase in whiteness was observed as the washing temperature increased. On the other hand, when compared to the detergents type, it has been found that the maximum whiteness is obtained with bleach-containing detergent. Also after washing with base detergent, fabrics whiteness index was obtained higher than washing with only water.

When the tensile strength values of the fabrics washed in various conditions were examined, it was seen that the strength values were not affected unfavorable in the warp direction. This is thought to be due to the increase of number yarns in the unit area due to the tightness of the fabric structure. The tensile strength values of all washed fabrics showed a decrease with respect to the non-washed fabrics.

The tensile strength values decrease as the number of washings increases for all samples. The value of the tensile strength is also reduced by the temperature increase. In the first 10 washing cycles, the reduction in tensile strength is less pronounced, but after 50 washing cycle this reduction is significant.

In this study, the average polymerisation degree (DP) of cotton fabrics washed under different washing conditions was examined in detail. When the results of washing with bleach-containing and non-bleaching detergents were evaluated, there was a decrease in the DP value in comparison with washing with water. This decrease is thought to be due to the chemical effect of the detergent. As the temperature and number of washing increased in washing process, the average polymerization degree decreased because of fiber deterioration and mechanical damage. 


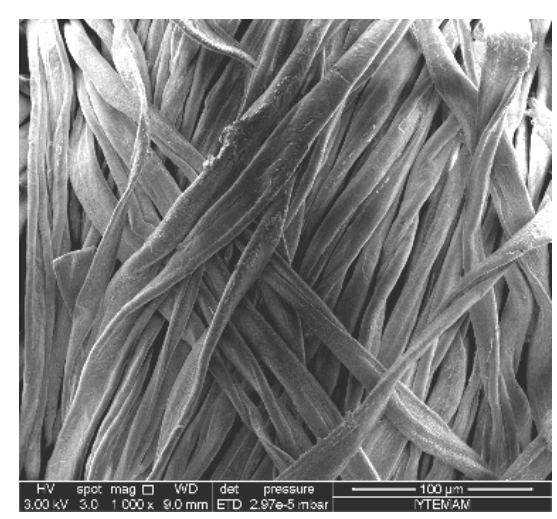

a)

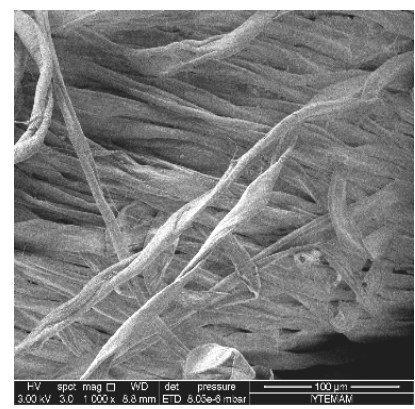

d)

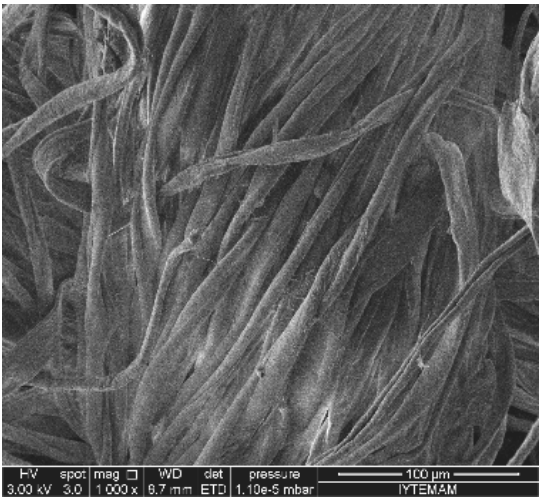

b)

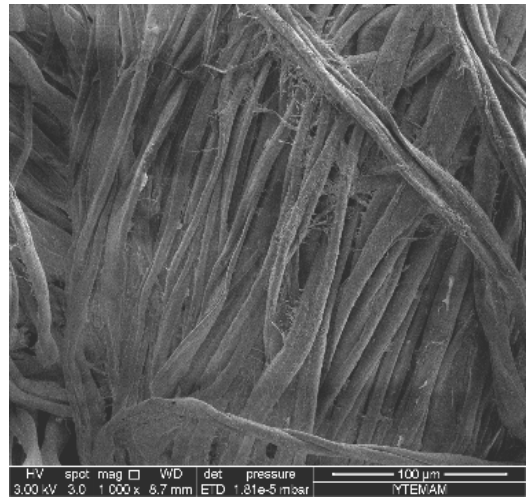

c)

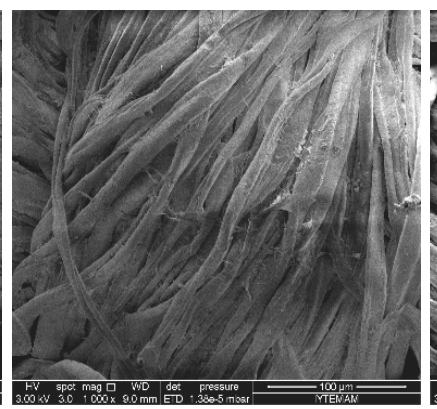

e)

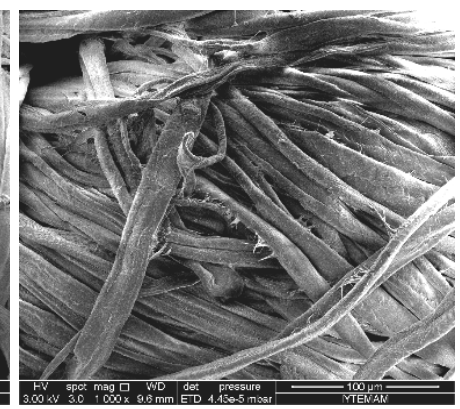

f)

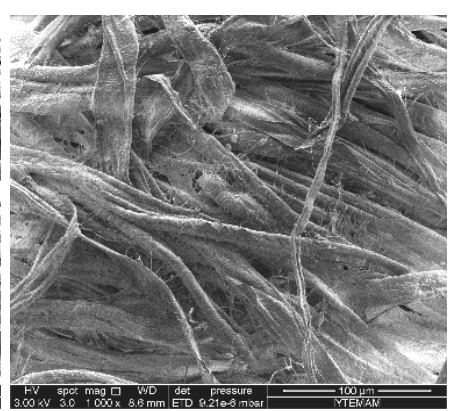

g)

Figure 4. SEM images of cotton fabrics (a) unwashed, (b) 10 washing with only water at $40^{\circ} \mathrm{C}$ (c) 50 washing with only water at $40^{\circ} \mathrm{C}$ (d) 10 washing with base detergent at $40^{\circ} \mathrm{C}$ (e) 50 washing with base detergent at $40^{\circ} \mathrm{C}(\mathrm{f}) 10$ washing with bleaching agent containing detergent at $40^{\circ} \mathrm{C} \quad$ (g) 50 washing with bleaching agent containing detergent at $40^{\circ} \mathrm{C}$ (at the magnification rate of 1000)

When the SEM images were examined in terms of the number of washings and temperature, it was observed that some deformation occurred on the surface depending on the mechanical effect with increasing temperature and number of washings. Also detergent has negative effects on fabrics surface.

By selecting the correct parameters in the washing process, the washing performance is at the targeted values. In domestic washing processes, the temperature and detergent variety parameters must be selected correctly when washing the cotton fabrics. In addition, consumers should avoid unnecessary washing operations on their clothes.

\section{Acknowledgements}

This study is supported by Ege University Scientific Research Projects Coordination Unit. through the project number of 13-TKUAM-008.

\section{REFERENCES}

1. Anand, S. C., . Brown, K. S. M., . Higgins, L. G, Holmes, D. A. ,. Hall, M. E and D. Conrad, 2002, "Effect Of Launderıng On The Dımensıonal Stabılıty And Distortion Of Knitted Fabrıcs", AUTEX Research Journal, 2(2): 85- 99.

2. Gündüz Balpetek, F.,. Seventekin, N., Özdoğan, E., Gülümser, T., Demir, A. 2011, "Challenges And Recommendations In The Evaluation Of Performances Of Home Type Laundry Detergents", Surfactant, Soap and Detergent Symposium and Exhibition (International Participant), Izmir, Turkey.

3. Raheel, M., Lien, M. D., "Effect Of Detergents On Wear And Appearance Characteristics Of Cotton Broadcloth", Textile Chemist and Colorist, $14(6)$ : 27-31.

4. Smulders, E., Rybinski, W., Nordskog, A., 2011, “Laundry Detergents”, https://doi.org/10.1002/14356007.a08_315.pub3

5. Toshıkj, E., Jordanov, I., Demboski, G., Mangovska, B., 2016,"Influence of Multiple Laundering On Cotton Shirts Properties”, Tekstil Ve Konfeksiyon 26(4): 393-399.

6. Pušıć, T., Soljačıć, I., Dekanıć, T.,"Cumulative effects of washing on properties of cotton fabrics and their blends”, 2014, Household and Personal Care Today, 9(4).

7. Pakula, C. , Stamminger, R., 2010, “Electricity and water consumption for laundry washing by washing machine worldwide”, Energy Efficiency,3:365-382.

8. Gooijer, H., Stamminger, R., 2016, "Water and Energy Consumption in Laundering Wordwide-A Review”, Tenside Surfactant Detergent, 53:402-409.

9. Kirsi, L., Boks, C., Klepp, I.G., 2011, “Potential for environmental improvements in laundering”, International Journal of Consumer Studies, 35: 254-264

10. Cılız, N., Mammadov, A., Turhan N., 2010, Life Cycle Assessment of Powder and Liquid Laundry Detergents", Boğaziçi University, Sustainable Development and Cleaner Production Center.

11. Fijan, S., Turk, S. Š., Neral, B., 2007, "The Influence of Industrial Laundering of Hospital Textiles on the Properties of Cotton Fabrics", Textile Research Journal, 77(4): 247-255. 
12. ASTM E313:2010, Standard Practice for Calculating Yellowness and Whiteness Indices from Instrumentally Measured Color Coordinates

13. ISO 13934-1:2013, Textiles -Tensile properties of fabrics -Part 1: Determination of maximum force and elongation at maximum force using the strip method

14. AATCC 82-2016, Fluidity of Dispersions of Cellulose from Bleached Cotton Cloth

15. Eduard Smulders; et al. (2007), "Laundry Detergents", Ullmann's Encyclopedia of Industrial Chemistry (7th ed.), Wiley, pp. 1184, doi:10.1002/14356007.a08_315.pub2

16. Fernandes G. E., Valenti D. J., Stenger P. C., Miracle G. S., Moon A. P., McDonnell M., Laundry Detergent Composition Comprising A Particle Having Hueing Agent and Clay", Patent No: US2013/0303428 A1, 2013, https://www.google.ch/patents/US20130303428?hl=de\&cl=en

17. Perincek, S., Duran, K., ,2016, "Optimization of enzymatic \& ultrasonic bio-scouring of linen fabrics by aid of Box-Behnken Experimental Design”, Journal of Cleaner Production, 135(1):1179-1188.

18. Collins L.M., Dziak J.J., Li R., 2009, "Design of Experiments with Multiple Independent Variables: A Resource Management Perspective on Complete and Reduced Factorial Designs", Psychol Methods, 14(3): 202-224.

19. Giovanni, M., 1983, "Response-surface methodology and product optimization", Food Technology, 37 (11): $41-45$.

20. Ferreira, S.L.C., Bruns, R.E., Ferreira, H.S., Matos, G.D. , David, J.M., Brandao G.C., Silva, E.G.P., Portugal, LA, Reis, P.S., Souza, AS, Santos WNL, 2007, "Box-Bhenken design: an alternative for the optimization of analytical methods", Analytica Chimica Acta, 597: 179-186

21. Luijkx, G. C. A., Hild, R., Krijnen, E. S., Lodewick, R., Rechenbach, T., Reinhardt, G., 2004, "Testing of the Fabric Damage Properties of Bleach Containing Detergents", Tenside Surfactants Detergents, 41(4): 164-168.

22. Singh, J. S., Ching, K. Y. C., Abdullah, L. C., Ching, K.Y., Razali, S., Neon, S. ,2018, "Optimization of Mechanical Properties for Polyoxymethylene/Glass Fiber/Polytetrafluoroethylene Composites Using Response Surface Methodology", Polymers, 10:338.

23. Cesa, F.S., Turra, A., Baruque-Ramos, J., 2017, "Synthetic fibers as microplastics in the marine environment: A review from textile perspective with a focus on domestic washings", Science of The Total Environment, 598: 1116-1129 